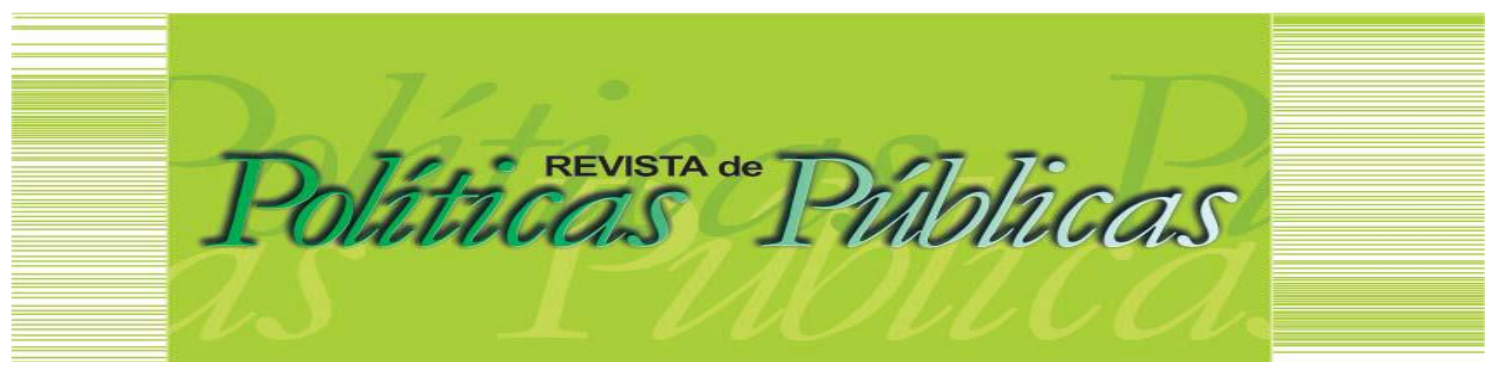

\title{
DESAFIOS E POSSIBILIDADES DE APLICAÇÃO DA JUSTIÇA RESTAURATIVA: casos de roubo e furto na cidade de Gurupi-TO
}

\author{
Verônica Silva Prado Disconzi ${ }^{1}$ \\ Lina Maria Gonçalves ${ }^{2}$ \\ Elvio Quintino Pereira ${ }^{3}$
}

\section{Resumo:}

O presente trabalho utiliza dados secundários sobre crimes e furtos, coletados pela Polícia Militar do Tocantins e $04^{\circ}$ Batalhão da Polícia Militar de Gurupi, nos biênios 2014-2015 e 2016-2017. Analisa-os por meio da Estatística Descritiva e propõe alternativa para ruptura do círculo vicioso do castigo físico e psicológico aos condenados por tais crimes. Como principais resultados, destaca o acréscimo superior a $70 \%$, nos furtos residenciais, no segundo biênio. Outro crime de grande incidência foi o de roubo a transeuntes. Diante das peculiaridades da cidade de Gurupi, conclui que uma medida adequada seria o desenvolvimento de Projeto de Justiça Restaurativa, por meio de convênio entre a Universidade de Gurupi e o Tribunal De Justiça do Estado do Tocantins, com a participação dos estagiários dos cursos de Direito e Psicologia desta Universidade.

Palavras chave: Criminalidade. Violência. Segurança Pública. Solução de Conflitos.

\section{CHALLENGES AND POSSIBILITIES OF THE APPLICATION OF RESTORATIVE JUSTICE: A case of robbery and theft in the city of Gurupi-TO}

\begin{abstract}
:
The present work uses secondary data on crimes and thefts, collected by the Tocantins Military Police and the 4th Battalion of the Military Police of Gurupi, in the 2014-2015 and 2016-2017 biennia. It analyzes them through Descriptive Statistics and proposes an alternative to break the vicious circle of physical and psychological punishment of those convicted of such crimes. As main results, there is an increase of more than $70 \%$ in residential robberies in the second biennium. Another crime of great incidence was the robbery of passersby. Given the peculiarities of the city of Gurupi, it is concluded that an adequate measure would be the development of a Restorative Justice Project, through an agreement between the University of Gurupi and the Court of Justice of the State of Tocantins, with the participation of the trainees of the courses of Law and Psychology of this University.

Keywords: Crime. Violence. Public Security. Conflict Resolution.
\end{abstract}

Artigo recebido em: 04/12/2018 Aprovado em: 28/03/2019 DOI: http://dx.doi.org/10.18764/2178-2865.v23n1p115-130

\footnotetext{
${ }^{1}$ Advogado. Mestre em Gestão de Políticas Públicas. Professora no Centro Universitário de Gurupi (UNIRG). Endereço: Avenida Antônio Neves da Silva s/ nº, Parque das Acácias, Gurupi-TO. CEP: 77400-000. E-mail: veronicadesconsi@gmail.com

2 Pedagoga. Doutora em Educação. Professora no Mestrado Profissional em Gestão Pública da Universidade Federal do Tocantins (UFTO). Endereço: Quadra 109 Norte, Avenida NS-15, ALCNO-14- Plano Diretor Norte | 77001-090 | Palmas/TO. E-mail: lina.mg@mail.uft.edu.br

3 Graduação em Engenharia Agronômica. Doutorado em Sociologia pela Universidade Federal da Paraíba (UFPB). Professor da UFTO. E-mail: elvio@uft.edu.br
} 


\section{INTRODUÇÃO}

A Constituição Federal (CF) de 1988, em seu artigo $5^{\circ}$, caput, evidencia que a sociedade, isto é , todos os cidadãos, possuem direitos.

Todos são iguais perante a lei, sem distinção de qualquer natureza, garantindo-se aos brasileiros e aos estrangeiros residentes no País a inviolabilidade do direito à vida, à liberdade, à igualdade, à segurança e à propriedade, nos termos seguintes. (BRASIL, 1988, Art. $5^{\circ}$ ).

Com base neste preceito, entende-se que cabe ao ente público, responsável pela segurança, atuar com tratamento indiferenciado entre as pessoas dessa nação. Como também fica evidente a vedação a este mesmo ente público que, no uso de suas atribuições, beneficie determinada classe social, em detrimento da outra. E ainda, que jamais atue de forma discriminatória, atribuindo culpa dos atos criminosos sempre às minorias, ao negro, ao pobre, ao favelado.

A CF de 1988 define, expressamente em seu art. 144", que é dever do Estado e direito de todos a preservação da ordem pública. $\mathrm{E}$, ainda, designa os órgãos responsáveis pela manutenção desse direito. Desse modo, o Estado assumiu legalmente a responsabilidade pela segurança da sociedade, competindo a ele a utilização de todas as ferramentas para reduzir a insegurança.

Porém, ao buscar nas bases históricas se 0 liame das condições sociais e econômicas reflete modificações na sociedade, se os resultados das políticas de segurança pública atingem, de maneira direta, a sociedade, se causam impactos positivos em relação à segurança pública; ou, contraditoriamente, se o Estado executa o formato Neoliberal-Penal, com apologia ao combate à criminalida pelo uso da força e da repressão, de forma indiscriminada, a segunda opção, parece prevalecer. Paradoxalmente, esta forma de combate à criminalidade, ao invés de garantir a segurança, rompe com ela, gerando a insegurança.

O Estado necessita resgatar o papel de protetor de toda a nação, rompendo o círculo vicioso do castigo físico e psicológico aos condenados por crimes. Sua atuação deve garantir, a toda a sociedade, direitos e condições igualitárias, acima de tudo, primando pelo bem-estar social. $\mathrm{Na}$ perspectiva neoliberal, a ideia de aglomerar várias pessoas em um espaço inadequado; de liberdade condicional, vigiada; do registro em bases de dados, que abalam a moral do ser humano, isolando-o do seio social, são ações entendidas como apropriadas para reabilitar o ser humano aos atos sociais. Entretanto, ao longo da história, elas não vêm surtindo efeitos positivos. Uma pessoa tratada com tamanha indiferença pelo governo e pela própria sociedade jamais se sentirá inserida ao meio social.

Nesse contexto, especialmente nos crimes de menor periculosidade, a sociedade precisa de alternativas, como por exemplo, de justiça restaurativa. Esta atua junto às partes envolvidas no 
conflito, que, em comum acordo, mantém a comunicação, visando restaurar a harmonia e sensatez, para solucionar a pendência com reparações condizentes com o delito cometido.

Nas palavras de Tony Marshall (1996, p. 37), a Justiça Restaurativa é "[...] um processo através do qual todas as partes envolvidas em uma ofensa particular se reúnem para resolver coletivamente como lidar com a consequência da ofensa e as suas implicações para o futuro". Para o alcance de uma justiça restaurativa, faz-se necessário um governo que prime pela execução de suas funções sociais, amparando toda a sociedade em suas necessidades basilares.

0 interesse pelos princípios e práticas da justiça restaurativa foi o motivador para desenvolver essa investigação, pois a busca de dados que comprovem estatisticamente a existência de um possivel crescimento (empiricamente constatado) nos crimes de roubo e furto em Gurupi, é elemento suficiente para justificar a apresentação de instrumentos direcionados a práticas alternativas para a solução da problemática. Neste caso, uma proposta de justiça restaurativa pode ser a alternativa para que a gestão pública consiga reduzir a prática de tais crimes, no município.

Assim, o objetivo primordial do trabalho foi o de analisar comparativamente os dados de furtos e roubos na cidade de Gurupi, Estado do Tocantins, durante os biênios 2014-2015 e 2016-2017, visando subsidiar uma proposta de políticas públicas para a área de segurança pública.

Foi realizada pesquisa documental, portanto, com uso de dados secundários referentes aos registros das ocorrências de furto e roubo realizados pelo IPEA, pela Polícia Militar do Estado do Tocantins e pelo $4^{\circ}$ Batalhão da Polícia Militar de Gurupi-To. A análise foi realizada por meio da estatística descritiva, na qual foram observadas as seguintes variantes: quantidade de crimes de furto $\mathrm{e}$ de roubos em comércios de 2014 a 2017; quantidade de crimes de furto e de roubos a residências de 2014 a 2017; quantidade de crimes de furto e de roubos a transeuntes de 2014 a 2017; quantidade de outros tipos de furto e de roubos de 2014 a 2017;

Realizou-se um comparativo de tais crimes quanto às naturezas apontadas entre os biênios 2014-2015 e 2016-2017, objetivando verificar quais dessas naturezas são as mais incidentes, para que o mecanismo de política pública a ser proposto pudesse ser direcionado ao foco principal. Utilizou-se a estatística descritiva com contagem de percentual. Os dados estatísticos serviram de base para a organização da proposta de oferta de mecanismo capaz de assessorar a gestão pública, quanto à segurança pública em Gurupi - TO.

Registra-se que a presente pesquisa não implicou riscos nem danos a eventuais participantes, por se realizar em bases documentais e desenvolver-se por meio de análise estatística descritiva, sem nenhuma identificação de participantes. 


\section{VIOLÊNCIA, CRIMINALIDADE E AÇÃO POLICIAL}

Abreu e Lourenço (2010) entendem que, nos dias atuais, a violência faz parte do cotidiano. Certamente são vivenciadas expectativas e frustrações no tocante à fragilidade da vida pública e social com relação à violência. Não são poucas as notícias e imagens que chegam aos lares brasileiros, expondo o sério problema da violência no país e no mundo. Contudo, não é somente por meio dos noticiários que a violência chega ao universo dos lares, mesmo a pequena cidade local traz em si o reflexo da criminalidade global.

Antigamente a violência estava ligada diretamente à pobreza, pois a ausência de oportunidades e a miséria impulsionavam esse tipo de comportamento, diante da indignação do distanciamento exacerbado das classes sociais. Geralmente essa violência ocorria em lugares mais pobres, como nas favelas, nas periferias, nos setores menos favorecidos. Abreu e Ferrari (2009) destacam que os indicadores do Departamento Penitenciário Nacional (DEPEN) demonstram que o crime no Brasil é praticado por homens na faixa etária de 14 a 26 anos de idade; da cor parda ou preta; residentes nas periferias e favelas dos grandes centros urbanos; com escolaridade que não ultrapassa o ensino fundamental; com renda por pessoa inferior a um salário mínimo e com um ambiente familiar marcado por um histórico de ausências e violência.

Zaffaroni (1991) e Zaffaroni e Pierangeli (2009) revelam que o que ocorre geralmente nestes casos de violência às camadas mais baixas da população é a aplicação da teoria da vulnerabilidade. Vulnerável aos abusos dos agentes do aparelho repressivo do Estado, as pessoas pobres que vivem ou atuam em lugares marginalizados, são o estereótipo para a prática do crime e, por isso, tornam-se as vítimas mais vulneráveis à violência de um modelo de segurança pública que ainda direciona sua atenção quase que exclusivamente para os pobres.

Mas apesar da permanência desse cenário, o perfil do crime mudou bastante nos últimos anos. Ou seja, o perfil do agente que pratica a violência e o crime foi ampliado com a inserção de jovens de classe alta e média. A cada dia são divulgados casos de agressões por diversão ou intolerância ao sexo, à mulher, aos negros, etc., ou seja, às minorias. É a banalização da vida e dos próprios atos de violência e criminalidade, como há tempos vêm sendo divulgadas pelos meios de comunicação.

Para Moser (1991), a violência é, conceitualmente, um comportamento social, já que pressupõe uma relação que envolve pelo menos duas pessoas, como a maioria das condutas humanas. É uma interação, na medida em que se origina e se efetiva na relação com o outro, 0 que condiciona e modela nosso comportamento. Existem, pelo menos, duas pessoas que participam dessa interação: 0 agressor e a vítima. 
Oliveira (2002) salienta que a violência é uma ação tipicamente humana e, como tal, carregada de racionalidade. Ainda que 0 ato violento seja intrínseco à agressividade, comparável ao instinto animal, o que diferencia o ser violento do agressivo é a existência do desejo de se cometer 0 ato de força ilegal.

A definição de Moser (1991), assim como as constatações de Oliveira (2002) evidenciam que a segurança está diretamente relacionada a não ocorrência de crimes, violências ou desordens. No sentido etimológico, o termo segurança designa a condição de estar seguro, a convicção ou a certeza da segurança. (OLIVEIRA, 2002).

Estar convicto de sua segurança é um direito de todo cidadão e dever do estado, por isso, são tão importantes efetivas políticas de segurança pública. Todavia, para tratar do tema, cabe antes entender a definição se insegurança.

Para Goldestein (2003), insegurança diz respeito ao conjunto de acontecimentos, dentro de uma determinada sociedade que ocasiona um comportamento social entranhado de medo, de ausência de paz e de ordem, e, sobretudo, de desespero em relação ao Estado e suas entidades responsáveis pela segurança.

Por esse motivo, entende-se que a repressão ao crime e à violência passa a ser considerada como uma das principais ações executadas pela força policial. Meireles (2007) descreve que "[...] a polícia é a instituição ou atividade estatal de proteção social, desenvolvida por meio de estruturas de poder e de força, garantidora da ordem social".

Portanto, resta provado que 0 ato de polícia vai além de prender criminoso. 0 poder de polícia é responsável por desenvolver todos os procedimentos para desvendar o crime, bem como apontar o agente ativo desse crime, garantindo à sociedade que este agente ficará isolado enquanto passa pela recuperação. Mas, como destacado anteriormente, o sistema penitenciário brasileiro não vem cumprindo a contento este papel recuperador.

Faz-se necessário e urgente o replanejamento das ações de repressão ao crime e promoção da segurança pública. Segundo Matos (2013), o planejamento da atuação estatal na área da segurança pública deve orientar-se pela prevenção e pelo combate sistêmico às causas estruturais da criminalidade, sobretudo, que não restrinja sua atuação exclusivamente à esfera penal, mas venha a contemplar igualmente novas ações políticas, sociais e econômicas que possam efetivamente contribuir para aumentar a sensação de segurança da sociedade como um todo.

Nesse contexto, a Justiça Restaurativa emerge como uma alternativa plausível, diante da falência estrutural do sistema criminal tradicional. 


\subsection{Por uma Justiça Restaurativa}

A Justiça Restaurativa surgiu na década de 1970 como uma maneira de o sistema judiciário se posicionar contrariamente ao punitivismo das políticas criminais. (HOYLE; CUNNEEN, 2010).

Destaca-se o embasamento legal da Justiça Restaurativa, que são: a Resolução nº. 26, de 28 de julho de 1999, que dispõe sobre Desenvolvimento e Implementação de Medidas de Mediação e de Justiça Restaurativa na Justiça Criminal; a Resolução $n^{0}$. 14, de 27 de julho de 2000, que formula sobre os princípios básicos da Justiça Restaurativa; e Resolução da ONU n 12 de 24 de julho de 2002, que recomenda princípios básicos para a utilização de Programas de Justiça Restaurativa em Matéria Criminal.

Ela possui algumas peculiaridades:

- Participação da vítima nos debates para a solução do conflito;

- Possibilidades do procedimento não implicar na prisão do acusado, ainda que ele admita a prática do ilícito;

- Transação extra ou judicial das partes; e,

- Os juízes e promotores abrem espaço a um enfrentamento interdisciplinar do conflito.

Azevedo (2005, p. 6) entende que a justiça restaurativa

[...] apresenta uma estrutura conceitual substancialmente distinta da chamada Justiça Tradicional ou Justiça Retributiva. A Justiça Restaurativa enfatiza a importância de se elevar o papel das vítimas e membros da comunidade ao mesmo tempo em que os ofensores (réus, acusados, indiciados ou autores do fato) são efetivamente responsabilizados perante as pessoas que foram vitimizadas, restaurando as perdas materiais e morais das vítimas e providenciando uma gama de oportunidades para diálogo, negociação e resolução de questões.

Segundo Melo (2005), os motivos que demonstram a emergência de um novo paradigma a partir da Justiça Restaurativa para o enfrentamento dos conflitos criminais são:

Primeiro: ela oportuniza outra percepção da relação entre 0 indivíduo e a sociedade "[...] no que concerne ao poder: contra uma visão vertical na definição do que é justo, ela dá vazão a um acertamento horizontal e pluralista daquilo que pode ser considerado justo pelos envolvidos numa situação conflitiva." (MELO, 2005, p. 57).

Segundo: a justiça restaurativa foca "[...] na singularidade daqueles que estão em relação e nos valores que a presidem, abrindo-se, com isso, àquilo que leva ao conflito". (MELO, 2005, p. 57).

Terceiro: se o foco está mais voltado para a relação do que para a resposta punitiva estatal, o próprio conflito e a tensão relacional adquirem outro estatuto, "[...] não mais como aquilo que há de ser rechaçado, apagado, aniquilado, mas sim como aquilo que há de ser trabalhado, laborado, 
potencializado naquilo que pode ter de positivo, para além de uma expressão gauche, com contornos destrutivos". (MELO, 2005, p. 57).

E em quarto, ela é uma alternativa ao "[...] modelo centrado no acertamento de contas meramente com o passado, a justiça restaurativa permite outra relação com o tempo, atenta também aos termos em que hão de se acertar os envolvidos no presente à vista do porvir". E, quinto, "[...] este modelo aponta para o rompimento dos limites colocados pelo direito liberal, abrindo-nos, para além do interpessoal, a uma percepção social dos problemas colocados nas situações conflitivas". (MELO, 2005, p. 57).

Para Antoine Garapon, Gros e Pech (2001, p. 253), a justiça restaurativa4 proporciona um verdadeiro "[...] deslocamento do centro de gravidade da justiça", pois "[...] atribui um rosto novo à justiça: reconstruir a relação no que ela tem de mais concreto. Tem como vizinhos homens de carne e osso, não a lei!" Com a quebra da centralidade da justiça criminal no acusado, a vítima passa a ter papel fundamental neste novo cenário, de forma a intimar "[...] o direito penal a reorganizar-se". Ainda para os autores, "[...] quando nos concentramos na vítima e já não no autor, a malvadez como vontade má deixa de ser central, o que exerce uma influência considerável sobre o sentido da pena. Esta já não pode pretender apontar uma intenção culpada." (GARAPON; GROS; PECH, 2001, p. 251).

Nesse sentido, a justiça restaurativa poderá colaborar para o fortalecimento da base dos direitos de cidadania e democracia, como refere Pallamolla (2010), mas também para a redução das desigualdades oriundas do sistema de justiça criminal, especialmente em relação aos menos favorecidos social e economicamente, que constituem a sua maior clientela, como lembra Leonardo Sica (2007)

A ideia não é abolir a justiça penal. Por isso a justiça restaurativa não é um produto pronto e acabado, ainda não tem condições de ter uma pretensão puramente abolicionista, todavia, pode-se pensar em uma redução da atuação do sistema penal e do sofrimento que esse sistema resulta às partes.

A própria Lei $n^{0}$ 13.675, de 11 de junho de 2018 que criou o Sistema Único de Segurança Pública, apresenta em suas diretrizes, no art. $5^{\circ}$, inciso III, a necessidade de criação de políticas designadas para o fortalecimento de ações para a preservação e solução pacífica dos conflitos sociais, inclusive, com a participação da sociedade civil, tornada possível, por exemplo, pelas ações de Justiça Restaurativa.

Apesar das garantias legais e do trabalho árduo das polícias, o que se observa é que a criminalidade cotinua avançando, o que justifica a busca por alternativas, de acordo com o contexto de cada localidade. Neste trabalho destacam-se os dados de crimes de roubos e furtos, no município de 
Gurupi, Tocantins e a proposição de alternativa para tais casos e contexto específico. Antes, porém, cabe fazer alguns esclarecimentos conceituais sobre os crimes de roubo e de furto.

Pelo crime de furto entende-se todo ato praticado sem haver violência ou ameaça em desfavor da vítima, onde a pessoa subtrai para si ou para outrem, objetos de qualquer natureza. Segundo o Código Penal Brasileiro (artigo 155\%), o crime de furto tem como consequência a pena de reclusão em regime fechado, ou seja, cumprido todo o período no presídio, pelo período de 1 a 4 anos, acrescido de multa.

Já o roubo é considerado quando o agente subtrai um bem alheio, praticando concomitantemente 0 ato de ameaça ou violência contra a vítima. 0 que torna o roubo especial em relação ao furto é justamente o emprego de violência ou grave ameaça à pessoa. (GRECO, 2018). 0 Código Penal traz em seu bojo, no art. $157^{\circ}$, as normas que conceituam o roubo.

O núcleo do tipo é subtrair, que equivale a retirar algo de alguém, invertendo o título da posse do bem. No âmbito do roubo, interpretando-se a ação nuclear em sintonia com os demais elementos do tipo, pode-se afirmar que subtrair significa apoderar-se da coisa móvel da vítima. Porém, esta ação ocorre mediante grave ameaça ou violência à pessoa, ou depois de havê-la, por qualquer meio, reduzido à impossibilidade de resistência. (MASSON, 2011).

O roubo é crime pluriofensivo, ou seja, afronta dois bens jurídicos tutelados pela lei penal, sendo estes: o patrimônio e a integridade física - se praticado com violência à pessoa, ou ao patrimônio e à liberdade individual, quando cometido mediante grave ameaça. Existe uma junção de crimes contra o patrimônio e contra a pessoa, mas o roubo foi inserido no título dos crimes contra 0 patrimônio pelo fato de que o resultado almejado pelo agente é a subtração patrimonial. (MASSON, 2011).

Portanto, enquanto o furto é classificado como um crime comum, podendo ser executado por qualquer agente, desconsiderando sua motivação, o roubo se diferencia, pois se trata de crime complexo, devido sua forma de execução, que pode ser desenvolvida por variadas ações, as quais são consideradas individualmente como crimes, como por exemplo, a lesão corporal, constrangimento ilegal e a morte da vítima.

Esclarecidas as questões conceituais (Quadro 1), cabe apresentar e analisar os dados estatísticos coletados, sobre furtos e roubos, em âmbito nacional, estadual e do município de Gurupi. 
Quadro 1 - Diferenças entre furto e roubo

\begin{tabular}{|c|c|c|}
\hline & FURTO & ROUBO \\
\hline Conceito & $\begin{array}{l}\text { Considera-se furto quando a pessoa pega um bem material de } \\
\text { outrem, sem que haja violência ou ameaça contra a vítima. }\end{array}$ & $\begin{array}{l}\text { Considera-se roubo quando o ato de } \\
\text { subtrair um bem material de outrem ocorre } \\
\text { por meio de violência ou ameaça. }\end{array}$ \\
\hline Base legal & Art. 155. & Art. 157. \\
\hline Vitima & $\begin{array}{l}\text { Está ausente, ou não verifica que aquele ato está sendo } \\
\text { realizado. }\end{array}$ & $\begin{array}{l}\text { Está presente, e sofre violência ou } \\
\text { ameaça. }\end{array}$ \\
\hline Tipo penal & Crime comum. & Crime complexo. \\
\hline Pena & Reclusão de 1 a 4 anos. & Reclusão de 4 a 10 anos e multa. \\
\hline Agravantes & $\begin{array}{l}\text { - A pena aumenta } 1 / 3 \text {, se o crime for praticado no período } \\
\text { noturno; } \\
\text { - Se o objeto for de pequeno valor, o juiz pode substituir a } \\
\text { pena de reclusão pela de detenção, diminuí-la de um a dois } \\
\text { terços, ou aplicar somente a pena de multa. } \\
\text { - Equipara-se à coisa móvel a energia elétrica ou qualquer } \\
\text { outra que tenha valor econômico. } \\
\text { Furto qualificado } \\
\text { - Houver emprego de explosivo, pena de reclusão de } 4 \text { a } 10 \\
\text { anos e multa: destruição ou rompimento de obstáculo à } \\
\text { subtração da coisa; houver abuso de confiança, ou mediante } \\
\text { fraude, escalada ou destreza; emprego de chave falsa; } \\
\text { concurso de duas ou mais pessoas. } \\
\text { - Subtração for de veículo automotor transportado para outro } \\
\text { Estado ou outro país, pena será de reclusão de } 3 \text { a } 8 \text { anos. } \\
\text { - semovente domesticável de produção, ainda que abatido ou } \\
\text { dividido em partes no local da subtração, pena de reclusão de } \\
2 \text { a } 5 \text { anos. } \\
\text { - substâncias explosivas ou de acessórios (fabricação ou } \\
\text { emprego), pena de reclusão de } 4 \text { a } 10 \text { anos e multa. }\end{array}$ & $\begin{array}{l}\text { - A pena aumente de } 1 / 3 \text { até a metade se: } \\
\text { fizer uso de arma; se for duas ou mais } \\
\text { pessoas; a vítima transporta valores e o } \\
\text { agente é conhecedor; subtração de veículo } \\
\text { automotor para transferir para outro Estado } \\
\text { ou país; mantiver a vítima em seu poder; } \\
\text { subtração de substâncias explosivas o } \\
\text { - A pena aumenta de } 2 / 3 \text { se: fizer uso de } \\
\text { arma de fogo; destruição de obstáculo com } \\
\text { explosivos; } \\
\text { - Se a violência resultar em lesão corporal } \\
\text { grave, a pena será de reclusão de } 7 \text { a } 18 \\
\text { anos e multa; } \\
\text { - Se resultar em morte, a pena será de } 20 \text { a } \\
30 \text { anos e multa; }\end{array}$ \\
\hline Exemplos & $\begin{array}{l}\text { Uma pessoa entra na casa de outra pessoa e pega algum } \\
\text { objeto sem que o dono veja, este seria classificado um crime } \\
\text { de furto, pois não houve ameaças ou violência. }\end{array}$ & $\begin{array}{l}\text { Se o dono da casa estiver presente quando } \\
\text { o assaltante invadir sua residência para } \\
\text { pegar um objeto, e esse empregar ameaça } \\
\text { ou violência contra a vítima. }\end{array}$ \\
\hline
\end{tabular}

Fonte: Elaborado pelos autores (2018).

\subsection{Crimes de roubo no Brasil, no Tocantins e em Gurupi}

Em relação aos crimes violentos não letais, contra o patrimônio, como é o caso do roubo, dados do Instituto de Pesquisa Ecônomica Aplicada (IPEA) referentes aos anos de 2015 e 2016, apresentam crescimento significativo, em todos os Estados. Registra-se a amostra de 2015/2016, tendo em vista que o IPEA divulgou, em 2017, apenas pesquisas referentes a homicídios.

No Brasil, em 2015 foram registrados 1.504 .008 (um milhão, quinhentos e quatro mil e oito) casos de roubo, mas em 2016 essa quantidade evoluiu para 1.726.757 (um milhão, setecentos e vinte e seis mil e setecentos e cinquenta e sete) registros. Portanto, esses dados demonstram que, no Brasil, os crimes contra o patrimônio (por roubo) sofreram um crescimento de $14,81 \%$.

No estado do Tocantins, segundo dados da Polícia Militar do Estado, os crimes de furto e roubo, por natureza, nos períodos de 2014 a 2017, totalizaram 55.863 casos, conforme detalhados no 
Tabela 1.

Tabela 1 - Número de ocorrências de furto e roubo, no Tocantins

\begin{tabular}{l|l|l|l|l|l}
\hline NATUREZA DOS CRIMES/PERÍODO & $\mathbf{2 0 1 4}$ & $\mathbf{2 0 1 5}$ & $\mathbf{2 0 1 6}$ & $\mathbf{2 0 1 7}$ & TOTAL \\
\hline Furto a transeunte & 322 & 331 & 187 & 121 & 961 \\
\hline Furto de carga & 4 & 0 & 3 & 0 & 7 \\
\hline Furto de veiculo & 1095 & 1121 & 992 & 975 & 4183 \\
\hline Furto em residência & 3313 & 3500 & 3391 & 2978 & 13182 \\
\hline Outros furtos & 3087 & 3187 & 2544 & 2284 & 11102 \\
\hline Outros roubos & 676 & 361 & 325 & 297 & 1659 \\
\hline Roubo a instituição financeira & 56 & 49 & 59 & 50 & 214 \\
\hline Roubo de carro-forte & 0 & 1 & 0 & 5 & 6 \\
\hline Roubo a transeunte & 2799 & 3879 & 4596 & 3568 & 14842 \\
\hline Roubo com restrição de liberdade da vítima & 5 & 8 & 7 & 6 & 26 \\
\hline Roubo de carga & 7 & 1 & 6 & 1 & 15 \\
\hline Roubo de veiculo & 569 & 733 & 1010 & 848 & 3160 \\
\hline Roubo em estabelecimento comercial ou de serviços & 978 & 1330 & 1070 & 719 & 4097 \\
\hline Roubo em residência & 313 & 551 & 778 & 641 & 2283 \\
\hline Roubo em transporte coletivo & 17 & 19 & 26 & 27 & 89 \\
\hline Total & $\mathbf{1 3 2 4 9}$ & $\mathbf{1 5 0 7 8}$ & $\mathbf{1 5 0 0 5}$ & $\mathbf{1 2 5 3 1}$ & $\mathbf{5 5 8 6 3}$ \\
\hline
\end{tabular}

Fonte: FORÚM BRASILEIRO DE SEGURANÇA PÚBLICA. Anuário Brasileiro de Segurança Pública. São Paulo, ano 12, 2018. Disponivel em: http://www.forumseguranca.org.br/publicacoes/6o-anuario-brasileiro-de-seguranca-publical. Acesso em: 8 ago. 2018.

A leitura da Tabela 1, revela uma oscilação dos casos de furtos no período, com aumento no biênio 2014/2015, de um total de 7.821 casos para 8.139. Já no biênio 2016/2017 teve uma redução para 7.117 em 2016 e 6.358 em 2017.

Os casos de roubos também aumentaram no biênio 2014/2015 de um total de 5.420 para 6932. Voltaram a aumentar para 7.877 casos, em 2016, novamente reduzindo para 6.162 casos, em 2017.

Cabe analisar que as oscilações ocorreram, mas os números sempre se mantiveram acima de cinco mil, para uma população aproximada de pouco mais de um milhão e meio de habitantes, em 2016. (INSTITUTO BRASILEIRO DE GEOGRAFIA E ESTATÍSTICA, 2018). Outro dado que chama a atenção refere-se ao número de furtos a residências e de roubo a transeuntes, que se mantiveram altos no estado do Tocantins, em todo o período.

E como esses dados se apresentam no município de Gurupi, objeto da presente pesquisa?

Dados coletados junto ao $4^{\circ}$ Batalhão da Polícia Militar do Município, apontam os índices mostrados na Tabela 2. 
Tabela 2 - Número de ocorrências registrada em Gurupi

\begin{tabular}{l|c|c|c|c|c}
\hline \multicolumn{1}{c|}{ NATUREZA DA OCORRÊNNCIA } & $\mathbf{2 0 1 4}$ & $\mathbf{2 0 1 5}$ & $\mathbf{2 0 1 6}$ & $\mathbf{2 0 1 7}$ & TOTAL \\
\hline Furto a transeunte & 118 & $\mathbf{7 1}$ & 62 & 38 & 289 \\
\hline Furto a veículo & 105 & 134 & 121 & 132 & 492 \\
\hline Furto em comércio & 127 & 132 & 87 & 129 & 475 \\
\hline Furto em residência & 332 & 238 & 539 & 447 & 1556 \\
\hline Roubo a transeunte & 384 & 500 & 469 & 388 & 1741 \\
\hline Roubo de veiculo & 32 & 59 & 88 & 53 & 232 \\
\hline Roubo em comércio & 164 & 202 & 157 & 72 & 595 \\
\hline Roubo em residência & 31 & 58 & 79 & 58 & 226 \\
\hline TOTAL/ANO & $\mathbf{1 . 2 9 3}$ & $\mathbf{1 . 3 9 4}$ & $\mathbf{1 . 6 0 2}$ & $\mathbf{1 . 3 1 7}$ & $\mathbf{5 . 6 0 6}$ \\
\hline
\end{tabular}

Fonte: TOCANTINS. Polícia Militar do Tocantins. $4^{\circ}$ Batalhão Da Polícia Militar - Gurupi. Comando do Policiamento do Interior. Palmas, [20--?]. Disponivel em: https://www.pm.to.gov.br/institucional/estrutura-geral/03---orgaos-deexecucao/02---cpi---comando-do-policiamento-do-interior/4-bpm---gurupi/ Acesso em: 8 ago. 2018.

A leitura da Tabela 2, mostra que as naturezas de crime, furto em residência e roubo a transeunte são os de maior ocorrência no município.

Em relação à natureza residencial, os índices dos crimes que não geram riscos à vítima (furto) são superiores àqueles que geram risco à vítima (roubo). Levando-se em consideração que durante os quatro anos foram registrados 1.556 (um mil, quinhentos e cinquenta e seis) de furtos em residência e que, do primeiro para o segundo biênio, houve um aumento de 416 (quatrocentos e dezesseis) constata-se um alarmante crescimento de mais de $70 \%$ nos casos de furtos em residências.

Em relação à natureza contra os transeuntes, os índices dos crimes que não geram riscos à vítima (furto) são inferiores àqueles que geram risco à vítima (roubo). Os casos de roubos a transeuntes, natureza de crime que, junto aos furtos em residência, chama a atenção das autoridades, seus índices tiveram um aumento de mais de 75\% de 2014 para 2015, com ligeira redução para 2016, que contiuou a cair em 2017, mas permanecendo maior que as ocorrências em 2014. No estado do Tocantins, os furtos em residências e outros tipos de furtos estão com índices muito superiores aos de roubos dessas mesmas naturezas. Em relação ao roubo os maiores índices são dos praticados contra o transeunte.

Essas e demais naturezas de roubos e furtos, registrados em Gurupi, mostrados na Tabela 2, tiveram oscilações para cima e para baixo, ao longo dos quatro anos, sendo o ano de 2016, 0 de maior índice geral de ocorrências. O comparativo entre a variação dos crimes de roubo e furto, por natureza, nos dois biênios, pode ser visualizada no Gráfico 1.

Além do crescimento exponencial, no segundo biênio, dos casos de furtos residenciais e de os casos de roubos a transeuntes, ser o segundo crime com maior índice dentro do período analisado, outros aspectos podem ser observados. 


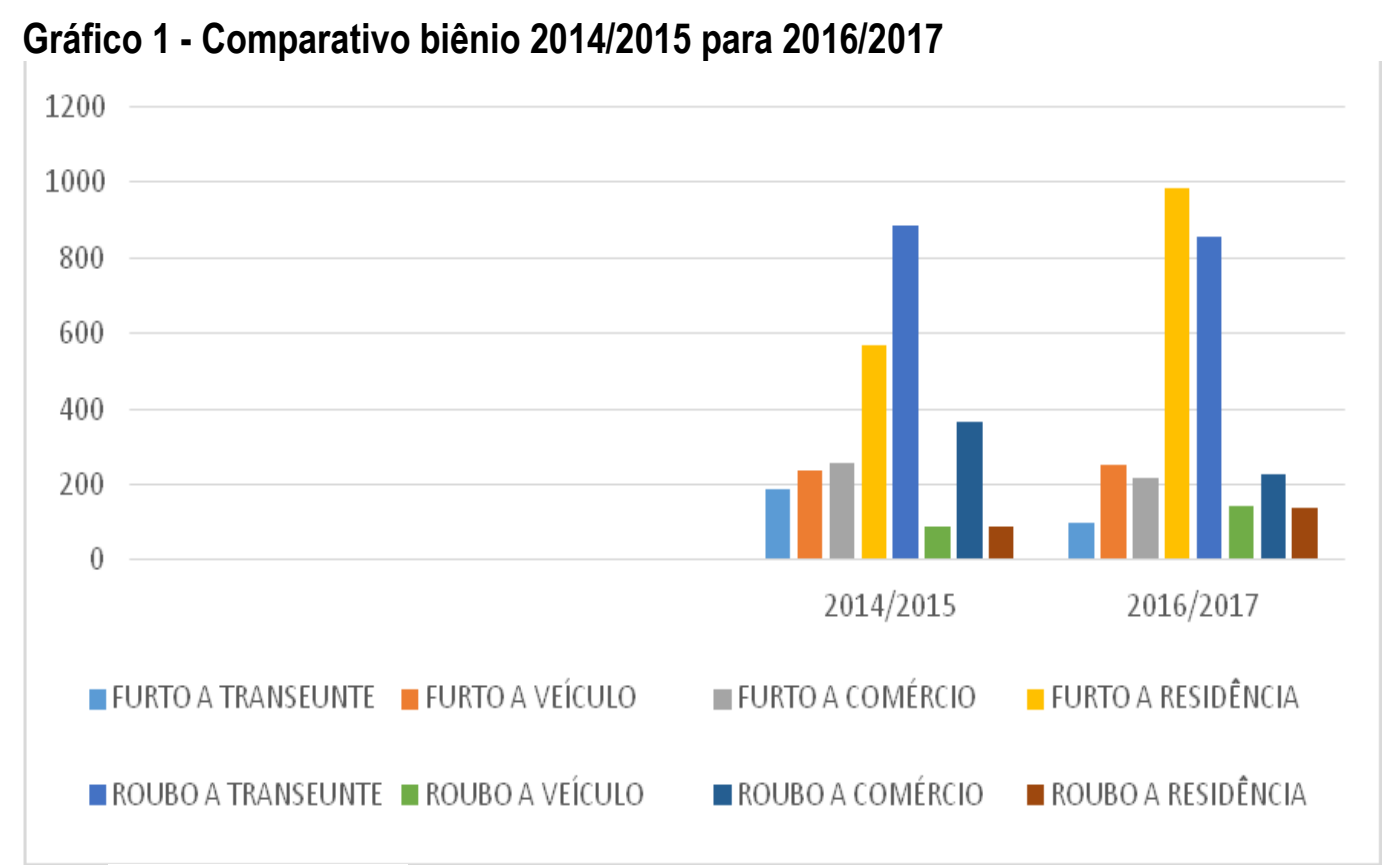

Fonte: (TOCANTINS, [20--?]).

Observa-se que houve uma redução nos crimes de furto a transeuntes, furto e roubo a comércio. Mas, houve uma elevação do roubo de veículos no segundo biênio, assim como de roubo residencial. O preocupante é que, por ser o roubo, tipo de crime que gera risco ou violência contra a vítima, estas sempre saem com sequelas físicas e psicológicas.

Cabe salientar que $0 \quad 4^{0}$ Batalhão da Polícia Militar de Gurupi-TO apresentou documentalmente que tais crimes possuem maior incidência nos setores: Centro, Nova Fronteira, Campo Belo, Alto da Boa Vista, Sol Nascente e Waldir Lins.

Diante dessas constatações, passa-se às considerações sobre a política pública capaz de contribuir com o poder público municipal, para minimizar as taxas de crimes de furto e roubo em Gurupi, levando em consideração a natureza de ocorrências residenciais, comerciais, veículos e transeunte.

A própria Lei $n^{0}$ 13.675/2018, que criou o Sistema Único de Segurança Pública, apresentou, em suas diretrizes, no art. $5^{\circ}$, inciso III, a necessidade de criação de políticas designadas ao fortalecimento de ações para a preservação e solução pacífica dos conflitos sociais. Também registrou a importância da participação da sociedade nas políticas de Segurança Pública.

No contexto da presente pesquisa, cabe destacar que os agentes de Segurança Pública: Polícia Federal, Polícia Rodoviária Federal, Polícia Ferroviária Federal, Polícia Civil, Polícia Militar e Corpo de Bombeiros Militar, apesar do preparo estrutural para executar sua missão, sofrem com as mazelas das incorporações que podem desviar o objetivo da salvaguarda dos direitos constitucionais 
Existe uma preocupação generalizada em relação à garantia da Segurança Pública. E a universidade pode contribuir com ações, principalmente ao que tange à garantia da dignidade da pessoa humana, sendo essa uma garantia dos direitos humanos.

Ações que possam minimizar as ocorrências dos crimes de roubo e furto, especialmente nas naturezas anteriomente demonstradas, necessitam urgentemente ser repensadas. Defende-se que uma alternativa viável, no contexto gurupiense, seria um projeto de justiça restaurativa, a ser desenvolvido com a participação dos estagiários dos cursos de Direito e de Psicologia, da Universidade de Gurupi.

\section{CONCLUSÃO}

Retomando o objetivo geral do trabalho, ressalta-se que foi analisar comparativamente os dados de furtos e roubos na cidade de Gurupi, Estado do Tocantins, durante os biênios 2014 2015 e 2016-2017, visando subsidiar uma proposta de política pública para a área de segurança pública.

Após estudos, chega-se à conclusão que a medida mais adequada para atender as necessidades da cidade de Gurupi é a realização de um Projeto de Justiça Restaurativa.

É preciso repensar um modelo de justiça que vá além do modelo punitivo e de coação, que vem sendo aplicado de forma fracassada. Também é preciso implantar medidas educativas, conscientizadoras, que reintegrem efetivamente 0 infrator à sociedade, com medidas que oportunize a solução dos conflitos de forma pacífica, evitando sua exclusão do seio social.

Para a aplicação desse método é importante superar paradigmas, estabelecer diálogo com instituições públicas e privadas e sociedade civil organizada, para que então se criem condições de aprimorar esse método e disseminar essa ideia pacificadora.

A política de Justiça Restaurativa busca técnica de solução de conflitos e de violências, através de escuta dos ofensores e das vítimas. Esse conceito foi desenvolvido pelo Conselho Nacional de Justiça, onde busca uma nova forma de compreender e executar o direito penal, em que as partes diretamente afetadas (ofensores e vítimas) irão decidir qual será a melhor opção para a reparação do dano.

Outras questões pertinentes, que devem ser consideradas, são a necessidade de integração entre os sistemas de segurança pública (as polícias militar, civil, rodoviária, etc), incluindo o esforço de integração entre as bases de dados, o que potencializaria o sucesso das ações de políticas de segurança pública, facilitando a identificação dos casos de reincidência, aqueles que precisam de intervenção mais efetiva, de assitência psicossocial, dentre outros. 
Uma segunda questão refere-se à necessidade de fortalecimento do Conselho Municipal de Segurança Pública, que existe no município de Gurupi, mas está inoperante. Seria fundamental sua participação ativa em um projeto de justiça restaurativa, bem como no estudo das possibilidades de intervenção no atual sistema prisional, com mudanças que permitam a ressociaização dos indivíduos.

Desse modo, o produto decorrente da presente pesquisa, ofe rtado para colaborar com a Segurança Pública de Gurupi, é a minuta de convênio entre Unirg e o Tribunal de Justiça, para posterior operacionalização da participação dos estagiários dos Cursos de Direito e Psicologia, da UnirG, em ações potencializadoras da Justiça Restaurativa em Gurupi.

Cabe destacar que já existe um convênio entre a Universidade Unirg, o Tribunal de Justiça e o Governo do Estado do Tocantins, que exerce um modelo de trabalho voltado para as atividades executadas na Vara Especializada de Violência Doméstica contra a Mulher e na Delegacia da Mulher de Gurupi, em que estagiários de Direito e Psicologia, devidamente acompanhados pelos supervisores de ambas as áreas, realizam atendimento e acompanhamento em processos judiciais.

Vislumbra-se, no formato de Justiça Restaurativa, uma possibilidade mais abrangente, em que tais atendimentos não sejam apenas realizados visando uma melhor qualidade de atendimento para formalizar os processos judiciais, mas como meio de solução de conflitos, onde algumas oportunidades de rodas de conversas ocorram envolvendo o ofensor e a vítima, para que estes demonstrem os danos materiais e psicológicos os quais resultaram no ato criminoso, acompanhados pelos estagiários e supervisores, em que ao final, chegar-se-á à conclusão de qual será a forma mais apropriada para se reparar o dano.

Nesse sentido, a vítima poderá entender as necessidades que impulsionaram o ofensor a praticar tal ato, e o ofensor entenderá que, muitas vezes, os danos passam da seara material, invadindo o âmbito psicológico, resultando em traumas de difícil reparação a todos os entes da família, atingindo, inclusive, até àqueles que não estiveram presentes no momento do ato criminoso.

Portanto, conclui-se que o modelo restaurativo é capaz de viabilizar medidas justas e duradouras, além de aperfeiçoar o modelo vigente de repressão dos atos crominosos de baixo grau de periculosidade e, assim, melhorar as condições de Segurança Pública, no município.

\section{REFERÊNCIAS}

ABREU, J. M.; FERRARI, M. C. Retrato social da discriminação racial e da marginalização criminal do negro no Brasil: um estudo do perfil sócio-racial dos detentos do Presídio Regional de Tijucas (SC).

Revista Brasileira de Ciências Criminais, São Paulo, ano 17, n. 77, p. 1-16, 2009. 
ABREU, J. M.; LOURENÇO, L. C. Mídia, violência e segurança pública: novos aspectos da violência e da criminalidade no Brasil. Âmbito Jurídico, São Paulo, n. 74, 2010. Não paginado.

AZEVEDO, A. G. O Componente mediação vítima-ofensor na justiça restaurativa: uma breve apresentação de uma inovação epistemológica na autocomposição penal. In BASTOS, M. T.; LOPES, C.; RENAULT, S. R. T. (orgs.). Justiça Restaurativa: coletânea de artigos. Brasília: MJ, PNUD, 2005.

BRASIL. Constituição da República Federativa do Brasil. Brasilia, DF: Senado Federal, 1988.

FORÚM BRASILEIRO DE SEGURANÇA PÚBLICA. Anuário Brasileiro de Segurança Pública. São Paulo, ano 12, 2018. Disponível em http://www.forumseguranca.org.br/publicacoes/6o-anuariobrasileiro-de-seguranca-publical.Acesso em: 8 ago. 2018.

GARAPON, A.; GROS, F.; PECH, T. Punir em Democracia: e a justiça será. Lisboa: Piaget, 2001.

GOLDSTEIN, H. Policiando uma sociedade livre. Tradução Marcello Rollemberg; revisão da tradução Maria Cristina P. da Cunha Marques. São Paulo: Universidade de São Paulo, 2003.

GRECO, R. Código Penal Comentado. 12. ed. Niteroi: Impetus, 2018.

HOYLE, C.; CUNNEEN, C. Debating Restorative Justice. Oxford e Portland: Hart Publishing, 2010.

INSTITUTO BRASILEIRO DE GEOGRAFIA E ESTATISTTICA. Estimativas populacionais para os municípios e para as Unidades da Federação brasileiros. Rio de Janeiro, 2015. Disponível em: https://ww2.ibge.gov.br/home/estatistica/populacao/estimativa2015/default.shtm. Acesso em: 20 maio 2018.

INSTITUTO DE PESQUISA ECONÔMICA APLICADA. Atlas da violência - 2017. Rio de Janeiro, 2017. Disponível em http://www.ipea.gov.br/portal/index.php?option=com_alphacontent\&view=alphacontent\&ltemid=357 Acesso em: 20 maio 2018.

MARSHALL, T. The evolution of restorative justice in Britain European Journal on Criminal Policy Research, Heidelberg, v. 4, n. 4, p. 21-43, 1996.

MASSON, C. Direito Penal: parte geral. 5 ed. São Paulo: Metodo, 2011.

MATOS, J. W. M. A construção do conceito de segurança pública na jurisprudência do supremo tribunal federal no século XXI. 2013. Dissertação (Mestrado em Direito) - Faculdade de Direito do Sul de Minas, Pouso Alegre, 2013.

MEIRELES, A. Violência e Polícia. [S. I.], 2007. Disponível em: www.comunidadesegura.org. Acessado em: 8 ago. 2018.

MELO, E. R. Justiça Restaurativa e seus Desafios Histórico-Culturais: um ensaio crítico sobre os fundamentos ético-filosóficos da justiça restaurativa em contraposição à justiça retributiva. In BASTOS, M. T.; LOPES, C.; RENAULT, S. R. T. (orgs.). Justiça Restaurativa: coletânea de artigos. Brasília: MJ; PNUD, 2005. p .53-78. 
MOSER, G. A agressão. São Paulo: Ática, 1991.

OLIVEIRA, N. V. (Org.). Insegurança pública: reflexões sobre a criminalidade e a violência urbana. São Paulo: Nova Alexandria, 2002.

PALLAMOLLA, R. P. A Justiça Restaurativa e o Acesso à Justiça: em busca da efetivação dos direitos fundamentais. In BERTOLDI, M. R.; OLIVEIRA, K. C. S. de (coord.). Direitos Fundamentais em Construção: estudos em homenagem ao Ministro Carlos Ayres Britto. Belo Horizonte: Forum, 2010.

SICA, L. Justiça Restaurativa e Mediação Penal: o novo modelo de justiça criminal e de gestão do crime. Rio de Janeiro: Lumen Juris, 2007.

TOCANTINS. Polícia Militar do Tocantins. $4^{\circ}$ Batalhão Da Polícia Militar - Gurupi. Comando do Policiamento do Interior. Palmas, [20--?]. Disponível em:

https://www.pm.to.gov.br/institucional/estrutura-geral/03---orgaos-de-execucao/02---cpi---comando-dopoliciamento-do-interior/4-bpm---gurupi/ Acesso em: 8 ago. 2018.

ZAFFARONI, E. R. Em busca das penas perdidas: a perda de legitimidade do sistema penal. Rio de Janeiro: Revan, 1991.

ZAFFARONI, E. R.; PIERANGELI, J. H. Manual de Direito Penal Brasileiro. 8. ed. São Paulo: Revista dos Tribunais, 2009. 